\title{
Antibody response in rabbits to serotype-specific determinants in lipopolysaccharides from Moraxella catarrhalis
}

\author{
M. RAHMAN and T. HOLME \\ Microbiology and Tumorbiology Center, Karolinska Institute, S-171 77 Stockholm, Sweden
}

\begin{abstract}
Antibodies against the serotype determinant epitopes of Moraxella catarrhalis lipopolysaccharides (LPS) were demonstrated in sera from rabbits immunised with whole bacterial cells. Purified LPS preparations from eight strains of $M$. catarrhalis were used as antigens in enzyme-linked immunosorbent assays (ELISA) and immunoblotting. The serotype specificity of the antibodies was shown by neutralisation with LPS and with purified polysaccharide obtained from LPS prepared from strains belonging to different serotypes. In immunoblots, antisera against the $A$ and B LPS serotypes reacted only with LPS of its own type, confirming the presence of type-specific antibodies. A weak band was observed with type A LPS and antibody to type C, indicating cross-reactivity between the $A$ and $C$ serotypes. This cross-reaction can be explained on the basis of the known chemical structure of the LPS of the different serotypes. After heterologous absorption of sera, bands were obtained with homologous LPS antigen. These results suggest that the predominant antibody response in rabbits to LPS from $M$. catarrhalis is serotype-specific, unlike that previously observed in infected human patients.
\end{abstract}

\section{Introduction}

The lipopolysaccharide (LPS) of Moraxella catarrhalis lacks the O-antigenic side chain characteristic of enteric pathogens [1-3], thus being similar in general structure to the LPS of Neisseria meningitidis, $N$. gonorrhoeae, Haemophilus influenzae and Bordetella pertussis [4-9]. However, the LPS of these species vary in mol.wt, even within species, and variable banding patterns are often found after separation in SDS-PAGE [6-8, 10, 11]. Furthermore, their complexity has been demonstrated by analysis of the antigenic variability found in different isolates of each species $[6-8,11]$.

The serological properties of the $M$. catarrhalis LPS indicate a less variable structure [12]. Three major antigenic types can be distinguished, accounting for $95 \%$ of all strains. Structural studies have shown that the carbohydrate parts of the LPS of the different

Received 21 April 1995; revised version accepted 26 Sept 1995.

Corresponding author: Dr M. Rahman serotypes consist of branched polysaccharides with a common inner core $[2,13]$. Differences in terminal sugars appear to constitute the basis for the antigenic specificities of the three serotypes. A terminal $\alpha$-DGlcNAc-(1-2)- $\beta$-D-Glc was found to be specific for serotype A LPS $[2,3]$, a terminal $\beta$-D-Gal-(1-4)- $\beta$-DGlc for serotype $B$ (unpublished observation) and a terminal $\beta$-D-Gal-(1-4)- $\alpha$-D-GlcNAc for serotype $\mathrm{C}$ [13]. The common inner core of the three serotypes contains a terminal $\alpha$-D-Gal-(1-4)- $\beta$-D-Gal-(1-4)- $\alpha$-Glc epitope [2]. This epitope is also found in LPS from $N$. gonorrhoeae, $N$. meningitidis and $H$. influenzae $[14,15]$. Weak cross-reactions between $M$. catarrhalis and $N$. meningitidis have been described but not between $M$. catarrhalis and $H$. influenzae $[16,17]$. Cross-reactions between the different serotypes of $M$. catarrhalis, and in particular between serotypes A and $\mathrm{C}$, have been described [12].

Characterisation of the LPS of $M$. catarrhalis and its immunogenic epitopes would be useful for future studies of the possible protective capacity of anti-LPS antibodies. Antigenic similarities with other respiratory pathogens may be important for possible crossprotection. The present study investigated the presence 
of type-specific antibodies to $M$. catarrhalis in sera from immunised rabbits.

\section{Materials and methods}

\section{Bacterial strains}

Eight test strains of $M$. catarrhalis were used. Four of these were clinical isolates (RS 10, type $C ; 13$, type B; 26, type C; and 272, type A) [18] and four were strains from the culture collection of the University of Gothenburgh, Sweden (CCUG 18283, type A; 18284, type A; and 3292, type B) and the American Type Culture Collection (ATCC 25238, type A). Three strains representing the LPS serotypes A, B and C were obtained from Dr M. Vaneechoutte, Department of Medical Microbiology, University Hospital, Ghent, Belgium. These were designated B1 for type A, F17 for type B and B3 for type $C$ and were used as serotype reference strains.

\section{Preparation of antibodies and antigens}

Rabbit antisera were produced against the eight test strains as described previously [18]. Purified LPS and lipid-free polysaccharide (PS) were prepared as reported previously [2].

\section{Absorption of antisera}

All eight test strains and the LPS serotype reference strains were grown on sheep blood agar plates at $37^{\circ} \mathrm{C}$ overnight. The bacteria were then scraped off and washed three times in saline with centrifugation at $4000 \mathrm{~g}$. Bacteria were resuspended in phosphatebuffered saline, $\mathrm{pH} 7.5$ (PBS). One $\mathrm{ml}$ of the bacterial suspension $\left(10^{8} \mathrm{cfu} / \mathrm{ml}\right)$ was centrifuged at $5000 \mathrm{~g}$ and the pellet was resuspended in $1 \mathrm{ml}$ of a 1 in 10 dilution of rabbit serum in PBS and incubated for $4 \mathrm{~h}$ at $37^{\circ} \mathrm{C}$ on a shaker. The mixture was then centrifuged at $5000 \mathrm{~g}$ at $4^{\circ} \mathrm{C}$ and the supernate was collected. This was called 'absorbed serum' and was stored at $-20^{\circ} \mathrm{C}$ until use. For each antiserum, samples were absorbed with the homologous strain, the reference strains A, B, $\mathrm{C}$ and the other seven test strains.

\section{ELISA}

Flat-bottom microtitration plates (Immunolon II; Dynatech Laboratories, Virginia, USA) were coated with $100 \mu \mathrm{l}$ of LPS of each test strain $(10 \mu \mathrm{g} / \mathrm{ml})$ in $0.05 \mathrm{M}$ sodium carbonate coating buffer ( $\mathrm{pH}$ 9.4) by incubation overnight at room temperature. The plates were washed four times with PBS containing Tween $200.5 \%$ (PBST) and each LPS was then incubated in duplicate for $2 \mathrm{~h}$ at $37^{\circ} \mathrm{C}$ with $100 \mu \mathrm{l}$ of two-fold serial dilutions of homologous unabsorbed serum (positive control), homologous absorbed serum (negative control), and antiserum absorbed by the reference strains of serotype A, B and C. After washing four times with PBST, plates were incubated for $1 \mathrm{~h}$ at $37^{\circ} \mathrm{C}$ with $100 \mu 1$ of horseradish peroxidase-conjugated sheep anti-rabbit immunoglobin (Binding Site), diluted 1 in 1000 in PBS. After washing, the reaction was developed by adding $100 \mu \mathrm{l}$ of substrate containing 3,5,3',5'-tetramethyl-benzidine $(0.1 \mathrm{mg} / \mathrm{ml})$ first dissolved in DMSO $(10 \mathrm{mg} / \mathrm{ml})$ and then added to a solution of $\mathrm{H}_{2} \mathrm{O}_{2}$ $0.002 \%$ in $0.1 \mathrm{M}$ sodium acetate $(\mathrm{pH} 6.0)$. The reaction was stopped after $10 \mathrm{~min}$ by adding $50 \mu \mathrm{l}$ of $2 \mathrm{M} \mathrm{H}_{2} \mathrm{SO}_{4}$ and the plates were read at $450 \mathrm{~nm}$. The percentage inhibition of antiserum reactivity by absorption was calculated as described previously [19].

\section{LPS and PS inhibition ELISA}

LPS-coated plates were incubated for $2 \mathrm{~h}$ at $37^{\circ} \mathrm{C}$ with appropriate dilutions of homologous sera that had previously been incubated with two-fold serial dilutions of LPS or PS $(15 \mu \mathrm{g} / \mathrm{ml}$ to $0.029 \mathrm{mg} / \mathrm{ml})$ for $2 \mathrm{~h}$ at $37^{\circ} \mathrm{C}$. The remainder of the assay was as described above. Inhibition was calculated as percentage of reduction in absorbance compared to a control without inhibitor and the concentration required for $50 \%$ inhibition was determined for each inhibitor.

\section{SDS-PAGE and immunoblotting}

Each LPS preparation was run in SDS-PAGE as described previously [2] and the gel was equilibrated in cold transfer buffer $(25 \mathrm{mM}$ Tris- $\mathrm{HCl}$ containing $192 \mathrm{mM}$ glycine, $\mathrm{pH} 8.3$ ) for $30 \mathrm{~min}$. Electrophoretic transfer of the sample to a nitrocellulose membrane was done at $100 \mathrm{~V}, 250 \mathrm{~mA}$ for $1 \mathrm{~h}$ at $4^{\circ} \mathrm{C}$. Nonspecific reactions were blocked by overnight treatment with skimmed milk $2 \%$ in PBS. The nitrocellulose membrane was then washed three times for $10 \mathrm{~min}$ each with skimmed milk $0.5 \%$ in Tris-buffered saline (TBS), $\mathrm{pH} 7.5$, sliced into strips and used for three different sets of experiments. Firstly, five strips were incubated with homologous unabsorbed antiserum, homologous absorbed antiserum, and antiserum absorbed by the reference strains of serotypes A, B and C. Secondly, eight strips were incubated separately with each of the eight test strain antisera and thirdly, eight strips were incubated with homologous antiserum absorbed by each of the eight test strains. All the above absorption experiments were incubated for $1 \mathrm{~h}$ at $37^{\circ} \mathrm{C}$ on a horizontal shaker with each antiserum diluted 1 in 100 in skimmed milk $0.5 \%$ in TBS.

The strips were then washed three times for $10 \mathrm{~min}$ each with skimmed milk $0.5 \%$ in TBS, and then incubated for $1 \mathrm{~h}$ at $37^{\circ} \mathrm{C}$ with affinity purified horseradish peroxidase-conjugated goat anti-rabbit IgG (BioRad Laboratories, CA, USA) diluted 1 in 1000 in TBS. They were washed again three times for 5 min each with skimmed milk $0.5 \%$ in TBS. Finally, the colour was developed by adding substrate containing ice-cold methanol 16\%, 4-chloro-1-naphthol $0.05 \%, \mathrm{H}_{2} \mathrm{O}_{2} \quad 0.025 \%$ in TBS. 


\section{Results}

\section{Enzyme immunoassays}

The antibody response against serotype determinant epitopes of $M$. catarrhalis LPS was analysed by ELISA with sera absorbed by bacterial cells of homologous and heterologous serotypes. The results obtained with antiserum against strain CCUG 3292 (type B) show no significant inhibition of antibody binding after heterologous absorption (with inner core similarity), indicating the predominance of antibodies against serotype determinant epitopes (Fig. 1). Homologous absorption resulted in $98 \%$ inhibition. Similar results were obtained with all eight strains and their corresponding antisera.

To investigate a possible difference in reactivity of LPS immobilised on solid phase or free in solution and the possible role of antibodies to the common core of lipid A, LPS and PS were used as inhibitors in the ELISA. The concentrations of inhibitors required to give $50 \%$ inhibition of the homologous reaction between the solid phase LPS and antiserum are shown in Table 1. When type A LPS was used as inhibitor for the reaction between type A LPS and its homologous antiserum, $50 \%$ inhibition was obtained at concentrations of $0.13-0.30 \mu \mathrm{g} / \mathrm{ml}$, but no inhibition was recorded with type B or type C LPS (concentration $>15 \mu \mathrm{g} / \mathrm{ml}$ ). The corresponding concentrations for $50 \%$ inhibition of type B antiserum by type B LPS were $1.8-2.1 \mu \mathrm{g} / \mathrm{ml}$ and for type $\mathrm{C}$ antiserum and type C LPS $0.13-1.8 \mu \mathrm{g} / \mathrm{ml}$. Lipid-free polysaccharide derived from the LPS (PS) was used in similar inhibition experiments. The concentrations of PS required for $50 \%$ inhibition of homologous reactions were between 0.05 and $1.8 \mu \mathrm{g} / \mathrm{ml}$.

\section{Immunoblotting}

Immunoblotting was performed with LPS from the eight test strains with homologous antisera that were either unabsorbed, absorbed with the homologous strain or absorbed with the reference strains A, B or C. The immunoblot results for strain ATCC 25238

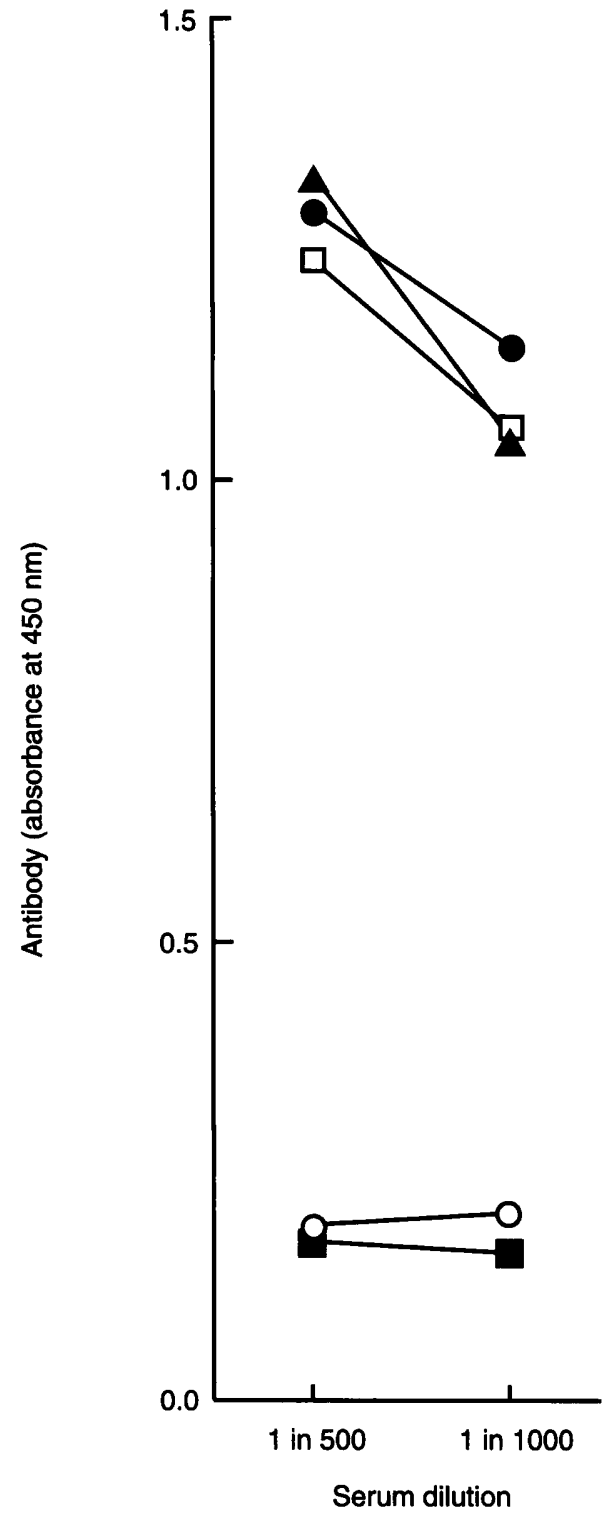

Fig. 1. Antibody response against serotype determinant epitopes of $M$. catarrhalis strain CCUG 3292. The microtitration plates were coated with purified LPS from strain CCUG 3292, and whole bacteria of the reference strains for serotype $\mathrm{A}, \mathrm{B}$, and $\mathrm{C}$ were used for absorption of antiserum against CCUG 3292: $-\square-$ homologous unabsorbed serum; - - homologous absorbed serum; serum absorbed with reference strains A $(-\boldsymbol{A}-)$, B (-O-), C (-O-).

Table 1. Concentration of LPS or purified O-polysaccharide (PS) required for $50 \%$ inhibition of the homologous reaction between LPS (solid phase) and antiserum in ELISA

\begin{tabular}{|c|c|c|c|c|c|c|c|c|c|c|c|c|}
\hline \multirow{2}{*}{$\begin{array}{l}\text { LPS } \\
\text { serotype }\end{array}$} & \multirow{2}{*}{$\begin{array}{c}\text { Solid } \\
\text { phase } \\
\text { strain no. }\end{array}$} & \multicolumn{8}{|c|}{ Concentration of LPS $(\mu \mathrm{g} / \mathrm{ml})$ for $50 \%$ inhibition from strain no. } & \multicolumn{3}{|c|}{$\begin{array}{c}\text { Concentration of } \\
\text { PS }(\mu \mathrm{g} / \mathrm{ml} \text { for } 50 \% \\
\text { inhibition) from strain no. }\end{array}$} \\
\hline & & 25238 & 272 & 18283 & 18284 & 3292 & 13 & 10 & 26 & 25238 & 3292 & 26 \\
\hline A & 25238 & 0.13 & 0.3 & 0.3 & 0.23 & $>15$ & $>15$ & $>15$ & $>15$ & 0.90 & $>15$ & $>15$ \\
\hline A & 272 & 0.15 & 0.13 & 0.18 & 0.18 & $>15$ & $>15$ & $>15$ & $>15$ & 0.10 & $>15$ & $>15$ \\
\hline A & 18283 & 0.13 & 0.18 & 0.13 & 0.23 & $>15$ & $>15$ & $>15$ & $>15$ & 0.18 & $>15$ & $>15$ \\
\hline A & 18284 & 0.18 & 0.23 & 0.23 & 0.13 & $>15$ & $>15$ & $>15$ & $>15$ & 0.18 & $>15$ & $>15$ \\
\hline B & 3292 & $>15$ & $>15$ & $>15$ & $>15$ & 2.1 & 1.8 & $>15$ & $>15$ & $>15$ & 1.8 & $>15$ \\
\hline B & 13 & $>15$ & $>15$ & $>15$ & $>15$ & 2.1 & 1.8 & $>15$ & $>15$ & $>15$ & 1.8 & $>15$ \\
\hline C & 10 & $>15$ & $>15$ & $>15$ & $>15$ & $>15$ & $>15$ & 0.13 & 0.45 & $>15$ & $>15$ & 0.18 \\
\hline $\mathrm{C}$ & 26 & $>15$ & $>15$ & $>15$ & $>15$ & $>15$ & $>15$ & 1.8 & 0.23 & $>15$ & $>15$ & 0.05 \\
\hline
\end{tabular}


(Fig. 2) show that serum absorbed by the type A reference strain developed no band with ATCC 25238 LPS (lane 3) indicating the total absorption of antiLPS antibodies. The presence of strong bands in lanes 4 and 5 shows the presence of antibodies to the serotype A determinant in serum after absorption with the reference strains $B$ and $C$ that have the same LPS core structure. Similar experiments with LPS preparations from all the other test strains and their homologous antisera confirmed the presence of serotype-specific antibodies (data not shown).

Immunoblotting with unabsorbed antisera was also performed with LPS from the eight test strains. When LPS from strain ATCC 25238 was immunoblotted with the eight antisera (Fig. 3), anti-LPS antibody recognised its homologous serotype as indicated by clear bands appearing on the strips incubated with antibody against type A LPS. No reaction was observed with type B antibody, but a weak band was observed in lane 8 with an antibody to type C LPS (RS 26). The same LPS was immunoblotted with absorbed antisera (Fig. 4). Eight samples of antiserum against strain ATCC 25238 were absorbed, each sample with whole cells of one of the eight test strains. Removal of anti-LPS serotype A antibody as indicated by absence of a band in lanes $1-4$, occurred with serum samples that had been absorbed with serotype A strains. Strips incubated with serum samples absorbed with strains of LPS serotypes B and $C$ showed no absorption of antibody to serotype A LPS and clear bands were observed.

\section{Discussion}

The role of LPS of $M$. catarrhalis in the pathogenesis of disease is largely unknown, and it is uncertain to what extent antibodies to LPS can afford protection against infection. Storm Fomsgaard et al. [20] have shown that purified LPS from $M$. catarrhalis is lethal for mice in doses similar to those of enterobacterial LPS. It has also been shown that bactericidal antibodies develop during infection with $M$. catarrhalis, but it has not been demonstrated against which antigens these antibodies are directed [21]. For future studies of infections caused by this species it is, therefore, important to acquire a detailed knowledge of the antigenic and biochemical properties of its LPS.

From the chemical structure of LPS of serotypes A and $C[2,13]$ and preliminary data on the structure of LPS of serotype $B$ it is known that a terminal trisaccharide, $\alpha$-Gal-(1-4)- $\beta$-Gal-(1-4)-Glc is common to all three serotypes. This trisaccharide is also found as the terminal part of glycolipids on the surface of human epithelial cells of mucous membranes. The
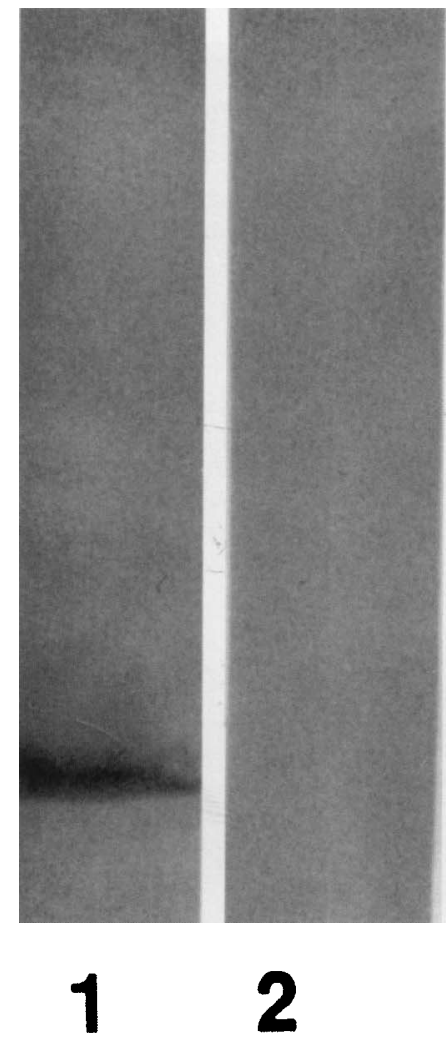

Fig. 2. Demonstration of the antibody response against the serotype A epitope by immunoblotting. Antigen in all lanes was purified LPS isolated from strain ATCC 25238 (type A). Antibody in lane: 1, homologous unabsorbed antiserum; 2, homologous absorbed antiserum; 3 , antiserum absorbed by reference strain $A ; 4$, antiserum absorbed by reference strain B; 5, antiserum absorbed by reference strain C. 

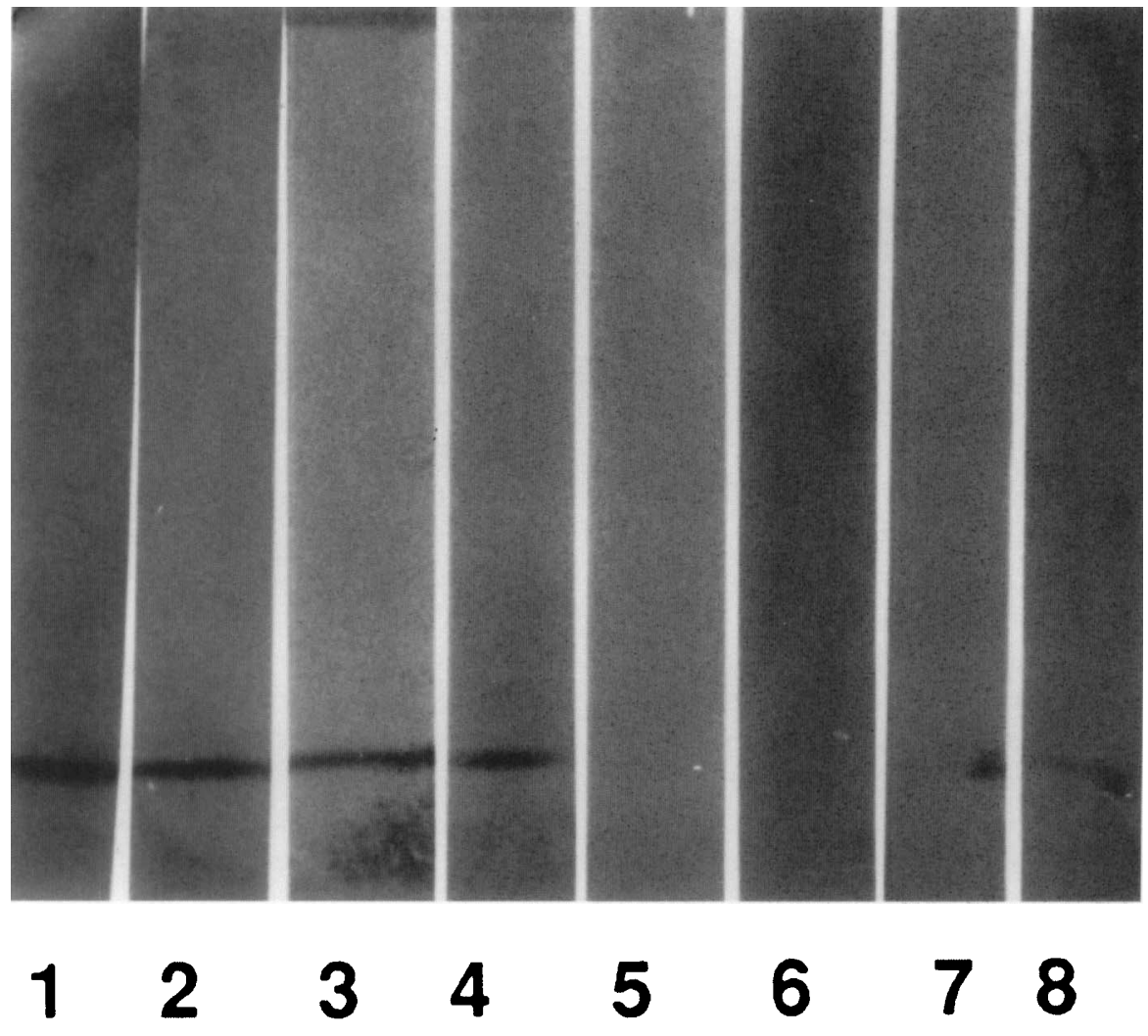

Fig. 3. Demonstration of specificity of reaction between rabbit antisera and purified LPS isolated from a serotype A strain of $M$. catarrhalis (ATCC 25238). Immunoblotting was performed with antisera against the following strains: lane 1, ATCC 25238; 2, RS 272 (type A); 3, CCUG 18283 (type A); 4, CCUG 18284 (type A); 5, CCUG 3292 (type B); 6, RS 10 (type C); 7, RS13 (type B); 8, RS 26 (type C). A weak band is seen in lane 8 indicating a cross-reaction between the type C strain RS 26 and the type A strain ATCC 25238.

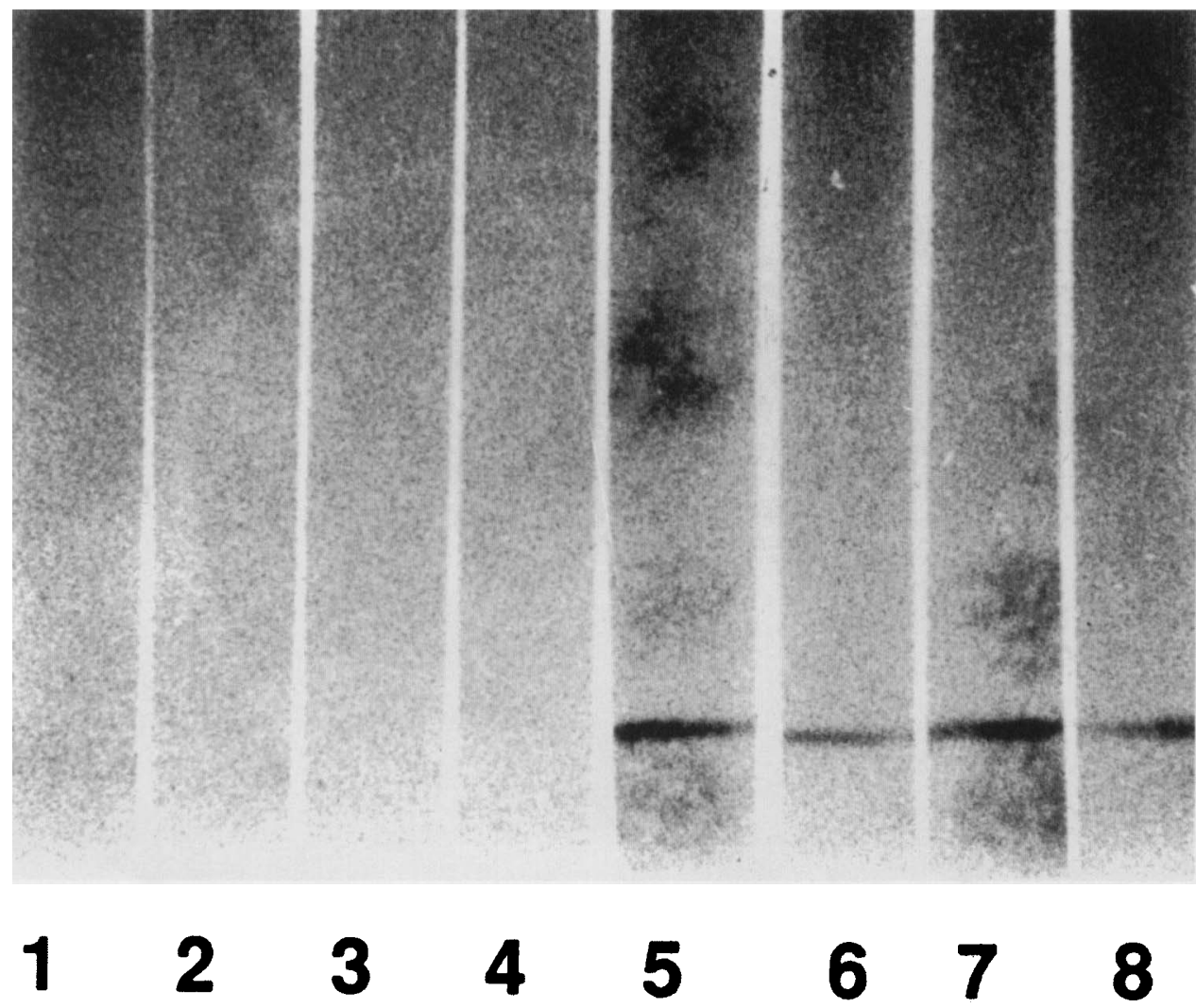

Fig. 4. Immunoblotting of LPS from a type A strain (ATCC 25238) with homologous antiserum absorbed by whole cells of the eight test strains. Serum absorbed by: lane 1, ATCC 25238; 2, RS 272 (type A); 3, CCUG 18283 (type A); 4, CCUG 18284 (type A); 5, CCUG 3292 (type B); 6, RS 10 (type C); 7, RS 13 (type B); 8, RS 26 (type C). 
terminal disaccharide $\alpha$-Gal-(1-4)-Gal of this trisaccharide is the receptor sequence in the uroepithelium for PapG, the adhesin expressed by pili of uropathogenic Escherichia coli [22]. It is also the receptor in the intestinal epithelium for the toxin secreted by Shigella shigae [22]. Another terminal disaccharide, $\beta$ Gal-(1-4)-GlcNAc, which is specific for serotype $C$, is also expressed in $H$. influenzae, $N$. gonorrhoeae and $N$. meningitidis, but coupled to a terminal sialic acid residue [23]. This disaccharide is also present in the human blood group antigen precursor, nLc4Cer [23]. Human cells have been shown to possess surface lectins that bind to various polylactosaminylglycans with a terminal $\beta$-Gal-(1-4)-GlcNAc [23]. LPS with a terminal $\mathrm{N}$-acetyl-lactosamine structure may have a potential for acting as a ligand for lectins. Expression of these epitopes may be a defence strategy for the bacteria and a way to escape the immune defence or may be used during the stage of colonisation or early invasion [24].

Phase variation of LPS antigens may occur at high frequency. Weiser et al. have shown that LPS epitope expression in vivo is different from that in vitro [25]. They have also shown that full length LPS is important for adhesion and invasion [24]. After invasion, bacteria with full length LPS are more susceptible to serum killing than those with short length LPS, and the organisms in which the terminal epitopes are switched off may be selected from among the population in response to the selective pressure of humoral immunity.

In sera from immunised rabbits, antibodies against the different LPS types were efficiently absorbed by whole bacteria of the corresponding type, showing that the LPS determinants were exposed on the surface of the cells used for absorption. In the demonstration of reactions between sera and the type A strain ATCC 25238 , no bands were visible with the type B antisera, whereas a weak band was observed with type C antiserum. As shown by Vaneechoutte et al. [12] cross-reactions are common between type $\mathrm{A}$ and type $\mathrm{C}$ strains. We have shown recently that the $\mathrm{O}$ polysaccharide preparations from strain RS26 (type C) is a mixture of four saccharides [13]. A minor component contains the same disaccharide epitope that constitutes the serotype-specific determinant of serotype A LPS, explaining the cross-reactivity between types A and C. Another serotype C strain, RS10, contained only type C-specific LPS [13]. Direct LPSELISA confirmed the cross-reaction between type A strains and RS26 and the absence of cross-reaction with RS10 (unpublished observations). The different structures of the LPS of the two serotype $C$ strains could explain the differences in the concentrations required for $50 \%$ inhibition in the inhibition-ELISA by LPS from the two serotype C strains (Table 1).

Type-specific neutralisation of antibodies by purified
LPS corresponded well with the absorption by whole cells, indicating that no immunodominant determinants were exposed on the isolated LPS molecules in addition to those exposed on the surface of whole bacteria. Thus, there is no indication that the antigenic differences demonstrated may depend on determinants which are not available on the surface of the bacteria but are exposed in purified preparations of LPS. The study also demonstrated that the polysaccharide isolated after mild acid hydrolysis of the LPS was equally effective in neutralisation of type-specific antibodies.

The absence of heterologous reactions in immunoblots of LPS from type A and B strains (Fig. 4) indicates that type-specific antibodies predominate. As common antigenic determinants of the LPS have been shown to give rise to antibody responses in both man and experimental animals, cross-reactions could have been expected, especially as the rabbits used in this study were immunised for an extended period. In agreement with the results obtained by ELISA, a weak crossreaction was demonstrated in immunoblots of type $A$ LPS with type $C$ antiserum.

A previous study demonstrated an antibody response in human patients against LPS antigens of $M$. catarrhalis during respiratory tract infections with this organism [19]. However, the antibody response was not specific; titre rises were observed in many patients against all three LPS serotypes, rather than against the serotype isolated from the patient. This finding suggests that antibodies directed against the common epitopes of the $M$. catarrhalis LPS could constitute a significant part of the human antibody response during infection. The difference in antibody response between immunised rabbits and patients during infection with $M$. catarrhalis may be due to species-dependent differences in the immune response, to differences in antigen presentation, or to altered epitope expression by the bacteria after invasion of the host. The rabbits used for production of the antisera in the present study were immunised with killed bacteria, and, therefore, no phase variation could occur. As mentioned earlier, phase variation is a common phenomenon in $H$. influenzae [25], and may occur in $M$. catarrhalis during infection. However, in the group of patients from whom $M$. catarrhalis was isolated, the titre rise was most pronounced against the A and B LPS serotypes, showing a preferential recognition of the most common serotypes. The human antibody response to $M$. catarrhalis LPS antigens during infection is thus complex, and the possible protective role of antibodies directed against different antigens has still to be evaluated.

This study was supported by the Swedish Medical Research Council (Project No. 8299) and the Karolinska Institute. A fellowship to R. M. from the Swedish Institute is gratefully acknowledged. We thank A. Weintraub for valuable advice and helpful discussions. 


\section{References}

1. Johnson KG, McDonald IJ, Perry MB. Studies on the cellular and free lipopolysaccharides from Branhamella caterrhalis. Can J Microbiol 1976; 22: 460-467.

2. Edebrink P, Jansson P-E, Rahman MM et al. Structural studies of the O-polysaccharide from the lipopolysaccharide of Moraxella (Branhamella) catarrhalis serotype A (strain ATCC 25238). Carbohydr Res 1994; 257: 269-284.

3. Masoud H, Perry MB, Brisson J-R, Uhrín D, Richards JC. Structural elucidation of the backbone oligosaccharide from the lipopolysaccharide of Moraxella catarrhalis serotype A. Can $J$ Chem 1994; 72: 1466-1477.

4. Flesher AR, Insel RA. Characterization of lipopolysaccharide of Haemophilus influenzae. $J$ Infect Dis 1978; 138: 719-730.

5. Tsai C-M, Boykins R, Frasch CE. Heterogeneity and variation among Neisseria meningitidis lipopolysaccharides. $J$ Bacteriol 1983; 155: 498-504

6. Schneider H, Hale TL, Zollinger W, Seid RCJ, Hammack CA, Griffiss JM. Heterogeneity of molecular size and antigenic expression within lipopolysaccharides of individual strains of Neisseria gonorrhoeae and Neisseria meningitidis. Infect Immun 1984; 45: 544-549.

7. Mandrell RE, Schneider H, Apicella M, Zollinger W, Rice PA, Griffiss JM. Antigenic and physical diversity of Neisseria gonorrhoeae lipooligosaccharides. Infect Immun 1986; 54: 63-69.

8. Griffiss JM, Schneider H, Mandrell RE et al. Lipooligosaccharides: the principal glycolipids of the neisserial outer membrane. Rev Infect Dis 1988; 10 Suppl 2: S287-S295.

9. Caroff M, Chaby R, Karibian D, Perry J, Deprun C, Szabó L. Variations in the carbohydrate regions of Bordetella pertussis lipopolysaccharides: electrophoretic, serological, and structural features. J Bacteriol 1990; 172: 1121-1128.

10. Mintz CS, Apicella MA, Morse SA. Electrophoretic and serological characterization of the lipopolysaccharide produced by Neisseria gonorrhoeae. J Infect Dis 1984; 149: 544-552.

11. Campagnari AA, Gupta MR, Dudas KC, Murphy TF, Apicella MA. Antigenic diversity of lipooligosaccharides of nontypable Haemophilus influenzae. Infect Immun 1987; 55: 882-887.

12. Vaneechoutte $M$, Verschraegen $G$, Claeys $G$, van den Abeele A-M. Serological typing of Branhamella catarrhalis strains on the basis of lipopolysaccharide antigens. $J$ Clin Microbiol 1990; 28: 182-187.

13. Edebrink P, Jansson P-E, Rahman MM, Widmalm G, Holme $T$, Rahman M. Structural studies of the O-antigen oligolysacchar- ides from two strains of Moraxella catarrhalis serotype C. Carbohydr Res 1995; 266: 237-261.

14. Mandrell RE, Griffiss JM, Macher BA. Lipooligosaccharides (LOS) of Neisseria gonorrhoeae and Neisseria meningitidis have components that are immunochemically similar to precursors of human blood group antigens. Carbohydrate sequence specificity of the mouse monoclonal antibodies that recognize crossreacting antigens on LOS and human erythrocytes. J Exp Med 1988; 168: 107-126.

15. Virji $M$, Weiser JN, Lindberg AA, Moxon ER. Antigenic similarities in lipopolysaccharides of Haemophilus and Neisseria and expression of a digalactoside structure also present on human cells. Microb Pathog 1990; 9: 441-450.

16. Goldblatt D, Seymour ND, Levinsky RJ, Turner MW. An enzyme-linked immunosorbent assay for the determination of human IgG subclass antibodies directed against Branhamella catarrhalis. J Immunol Methods 1990; 128: 219-225.

17. Jönsson I, Holme T, Krook A, Thorén M. Serological crossreactions between Moraxella (Branhamella) catarrhalis and other oropharyngeal bacteria. Eur J Clin Microbiol Infect Dis 1993; 12: 289-294.

18. Jönsson I, Holme $T$, Krook A, Rahman M, Thorén $M$. Variability of surface-exposed antigens of different strains of Moraxella catarrhalis. Eur J Clin Microbiol Infect Dis 1992; 11: 919-922

19. Rahman M, Holme T, Jönsson I, Krook A. Lack of serotypespecific antibody response to lipopolysaccharide antigens of Moraxella catarrhalis during lower respiratory tract infection. Eur J Clin Microbiol Infect Dis 1995; 14: 297-304.

20. Storm Fomsgaard J, Fomsgaard A, Høiby N, Bruun B, Galanos C. Comparative immunochemistry of lipopolysaccharides from Branhamella catarrhalis strains. Infect Immun 1991; 59: 33463349.

21. Chapman AJ, Musher DM, Jonsson S, Clarridge JE, Wallace RJ. Development of bactericidal antibody during Branhamella catarrhalis infection. J Infect Dis 1985; 15: 878-882.

22. Karlsson K-A. Animal glycosphingolipids as membrane attachment sites for bacteria. Annu Rev Biochem 1989; 58: 309-350.

23. Mandrell RE, McLaughlin R, Abu Kwaik Y et al. Lipooligosaccharides (LOS) of some Haemophilus species mimic glycosphingolipids, and some LOS are sialylated. Infect Immun 1992; 60: 1322-1328.

24. Weiser JN. The oligosaccharide of Haemophilus influenzae. Microb Pathog 1992; 13: 335-342.

25. Weiser JN, Love JM, Moxon ER. The molecular mechanism of phase variation of $H$. influenzae lipopolysaccharide. Cell 1989; 59: $657-665$. 